\title{
Taxonomical and Phytochemical Characterisation of 10 Stachys Taxa Recorded in the Balkan Peninsula Flora: A Review
}

\author{
Vjera Bilušić Vundać
}

University of Zadar, Department of Health Studies, Splitska 1, 23000 Zadar, Croatia; vjerab_2000@yahoo.com

Received: 21 September 2018; Accepted: 22 January 2019; Published: 29 January 2019

\begin{abstract}
The genus Stachys is one of the largest genera of the Lamiaceae, and it comprises about 300 species. Some species are highly polymorphic, with a number of infraspecific taxa. The aim of the present review is to summarise the available knowledge on 10 taxa belonging to the Balkan Peninsula flora (S. alpina L., S. germanica L., S. menthifolia Vis., S. obliqua Waldst. Et Kit., S. officinalis (L.) Trevis., S. palustris L., S. recta L. subsp. recta, S. recta L. subsp. subcrenata (Vis.) Briq., S. salviifolia Ten., and S. sylvatica L.) in order to enable insight into the identified biologically active substances and their possible application in intrageneric differentiation.
\end{abstract}

Keywords: Lamiaceae; Stachys; essential oil; fatty acids; amino acids; flavonoids; iridoids; phytochemical; chemotaxonomy

\section{Introduction}

Stachys L. (woundwort) comprises approximately 300 species, and is considered one of the largest genera of Lamiaceae, with nearly worldwide distribution. Most of these species occur in the warm temperate regions of the Mediterranean and southwest Asia, with secondary centres in North and South America and southern Africa; woundwort is not found in Australia and New Zealand [1]. The genus comprises 19 taxa in the flora of Croatia and neighbouring areas (Domac, 1973), among which eight species are endemic to the Balkan Peninsula or even narrower regions [2]. This article comprises phytochemical and taxonomical characterisation of 10 taxa: S. alpina L., S. germanica L., S. menthifolia Vis., S. obliqua Waldst. Et Kit., S. officinalis (L.) Trevis., S. palustris L., S. recta L. subsp. recta, S. recta L. subsp. subcrenata (Vis.) Briq., S. salviifolia Ten., and S. sylvatica L. among the presented species. Presented data also include chemotaxonomical guidance for highly polymorphic species of $S$. recta, with a proposal for the differentation of two of the presented subspecies [1-7]. S. menthifolia Vis. is not mentioned by Domac, but is listed in Flora Europaea as endemic species for Balkan Peninsula, and has been identified on several localities of Croatia and Montenegro [3,8,9]. The aim of present review is to find a scientific literature that contains research on the biologically active compounds of presented Stachys taxa belonging to the Balkan Peninsula flora and to report the findings on the chemotaxonomical composition that could help to differentiate within the Stachys spp. Presented data also include chemotaxonomical guidance for highly polymorphic species of $S$. recta, with a proposal for the differentation of two presented subspecies $[1-7,10]$.

\section{Taxonomy and Systematics}

Genus Stachys is composed of annual or perennial herbs or subshrubs that are hispid or soft-pubescent. Leaves are sesille or stipulate, blade oblong to ovate, with serrate to crenate margins. Flowers are sessile or short-stalked, with two or more clustered in the axils of the leaves on the upper part of the stem. The calyx is bell-shaped, and has five lobes or teeth. Corolla has a narrow 
tube, generally with a short, pouched spur on the lower side of the tube. The upper lip is erect or generally parallel to tube axis, concave, entire (notched), and generally hairy, and the lower lip is perpendicular to the tube axis or reflexed, three (two)-lobed, and glabrous to hairy. The nutlets are oblong to ovoid $[2-7,10]$.

S. alpina L. (alpine woundwort) is a green, hirsute, glandular perrenial up to $100 \mathrm{~cm}$ in height. It grows in shadow on limestone soils from mountainous to subalpine areas [2,3,10] [Figure 1].

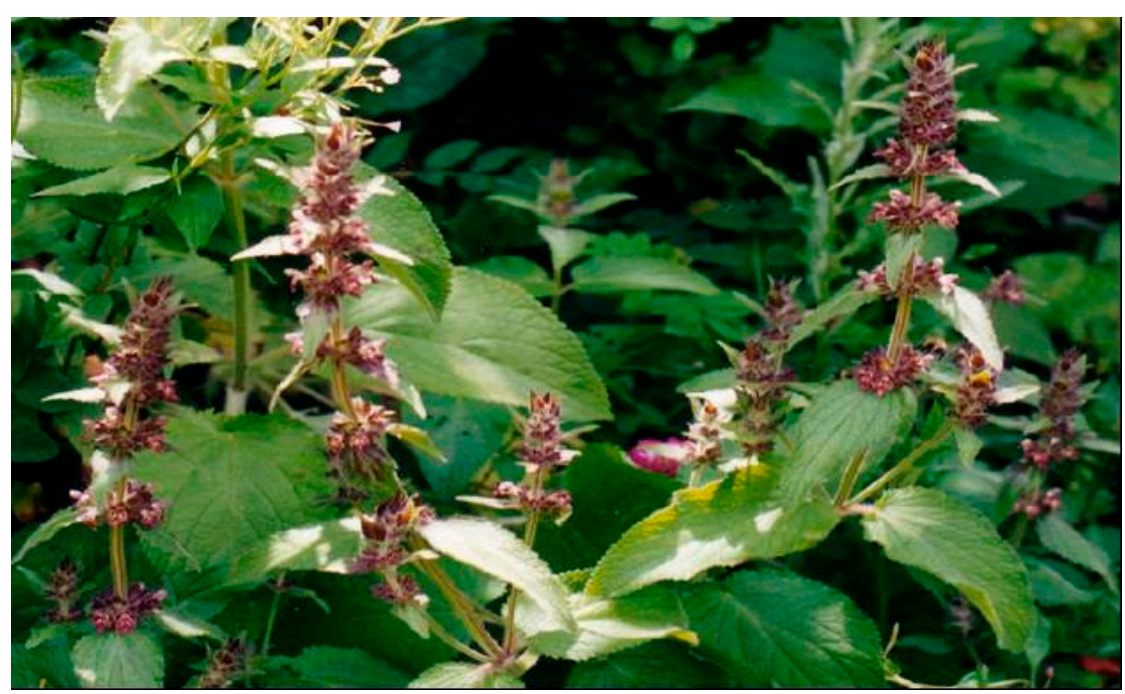

(a)

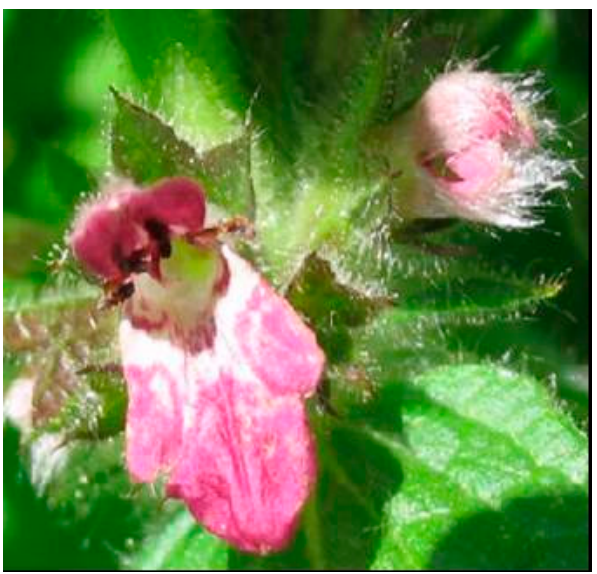

(b)

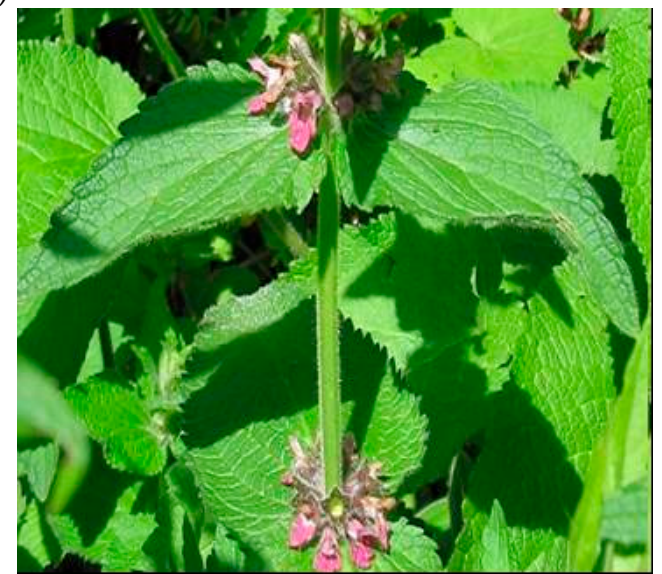

(c)

Figure 1. Stachys alpina L. (a) plant in flowering stage; (b) detail of the flower; (c) detail of leaf.

S. officinalis L. (betony) is a perennial herb of $15-60 \mathrm{~cm}$ height, with sparse hairs, a short woody rhizome, well-marked basal rosettes, and erect, simple, or slightly branched stems. Betony occurs in open woods, stony grassy places, and dry meadows from the sea level up to $1600 \mathrm{~m}[2,3,10,11]$ [Figure 2].

S. palustris L.(marsh woundwort) is a sparsely to densely hairy perennial plant of shady spots in marshes, bogs, ponds, lakes, and stream margins, damp places, roadside verges, and as a weed in cultivated fields growing up to $120 \mathrm{~cm}$ from a creeping rhizome [2,3,10] [Figure 3]. 


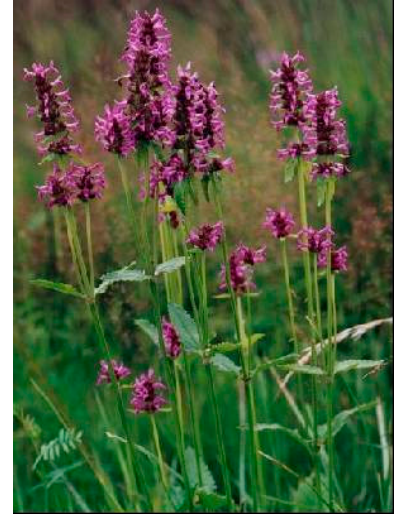

(a)

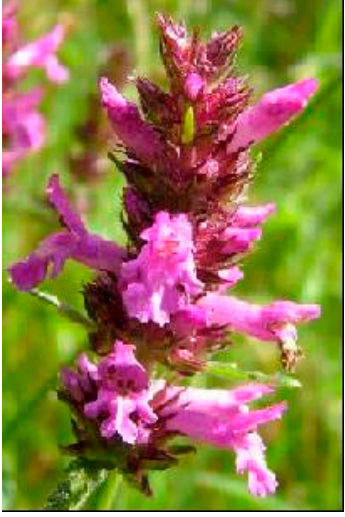

(b)

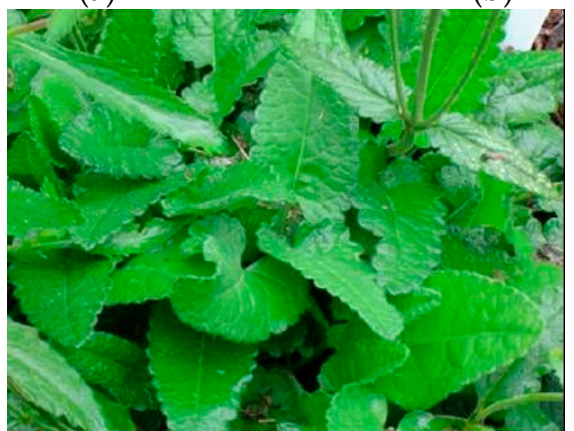

(c)

Figure 2. S. officinalis L. (a) plant in flowering stage; (b) detail of the flower; (c) detail of leaf.

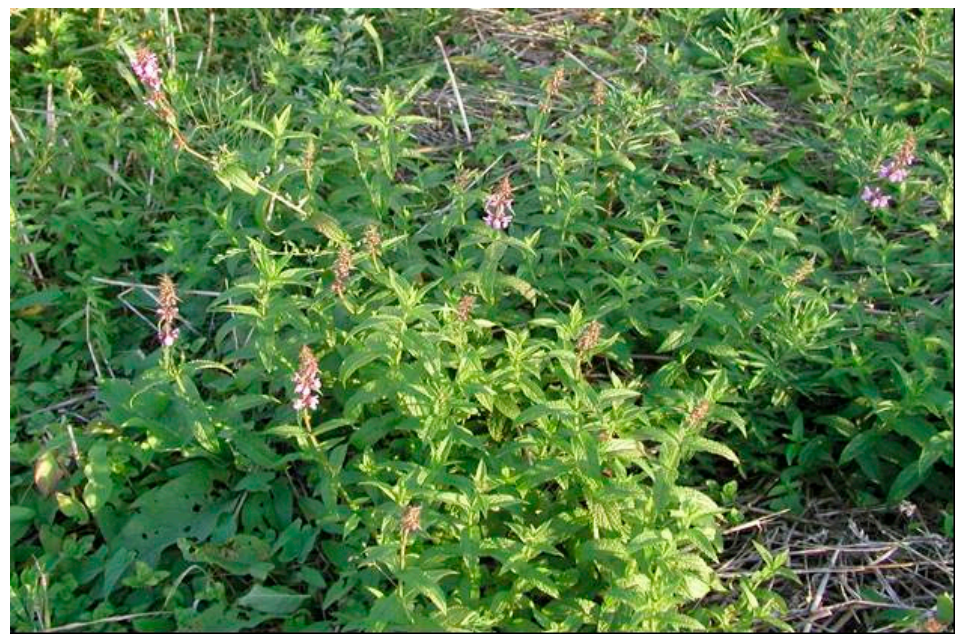

(a)

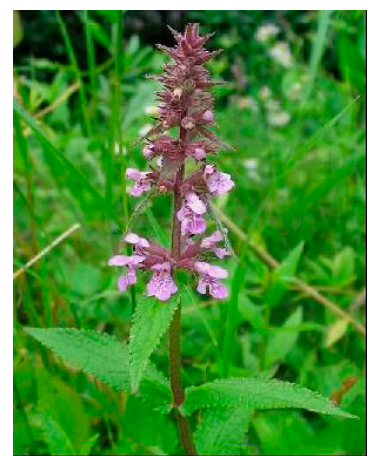

(b)

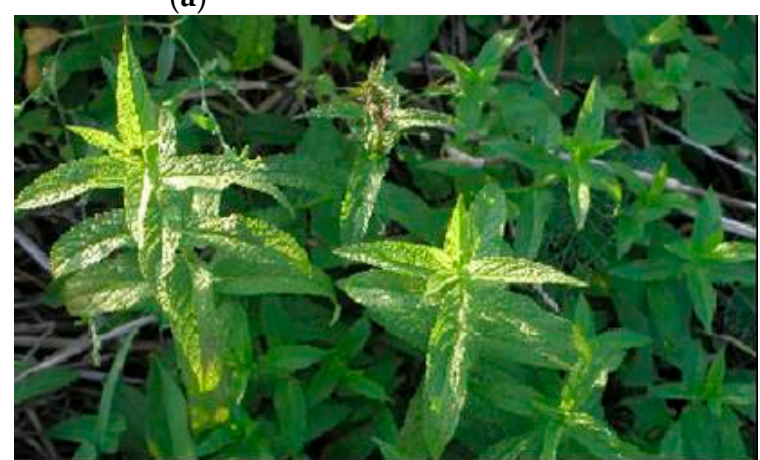

(c)

Figure 3. S. palustris L. (a) plant in flowering stage; (b) detail of the flower; (c) detail of leaf. 
S. recta L. subsp. recta (perennial yellow woundwort) is erect or ascending, subglabrous to sparsely hirsute, and usually an eglandular plant of up to $100 \mathrm{~cm}$ in height, which grows on different dry and stony habitats $[2,3,10]$ [Figure 4$]$.

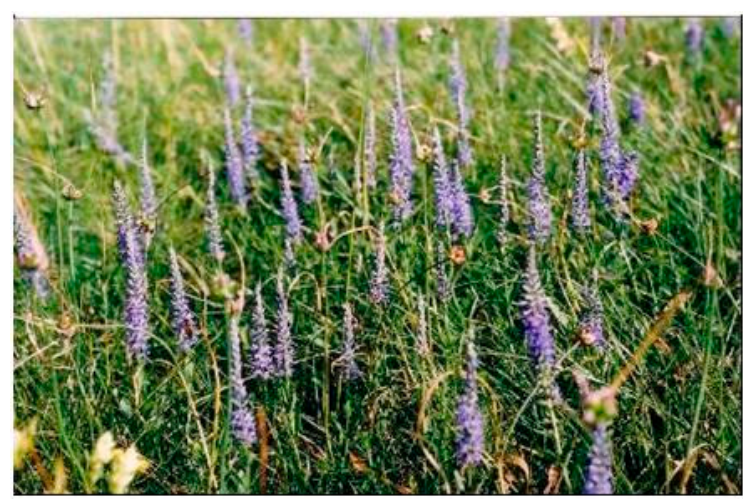

(a)

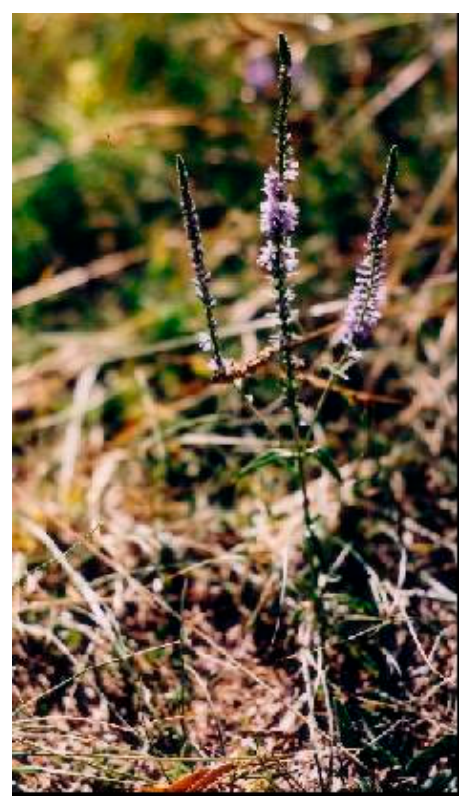

(b)

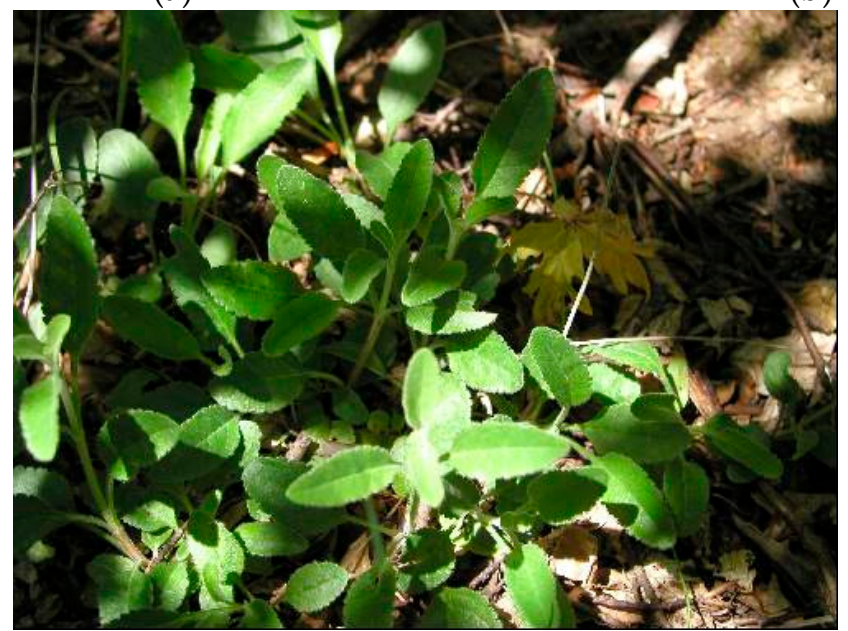

(c)

Figure 4. S. recta L. subsp. recta (a) plant in flowering stage; (b) detail of the flower; (c) detail of leaf.

S. recta L. subsp. subcrenata (Vis.) Briq. has a very similar appearance and distribution as compared to the S. recta L. subsp. Recta, but has narrower leaves and often a glandular calyx with unequal teeth $[2,3,10,11]$ [Figure 5].

S. sylvatica L. (hedge woundwort) is an erect and hirsute perennial found in shady spots in woodland, forests, roadsides, alpine meadows, and grasslands, growing up to $120 \mathrm{~cm}$. It differs from marsh woundwort in habitat preference, the broader leaves, and its characteristic, unpleasant smell when crushed, but the two can hybridise where they co-exist [2,3,10,11] [Figure 6]. 


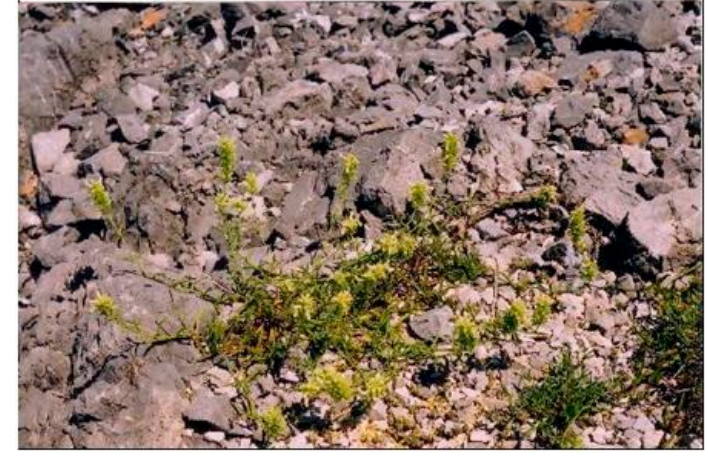

(a)

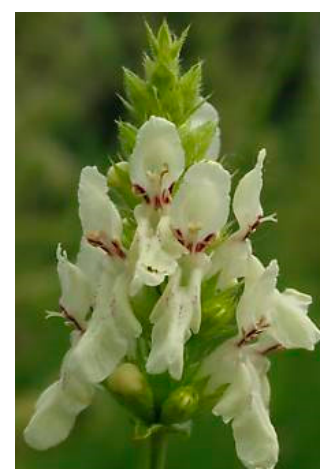

(b)

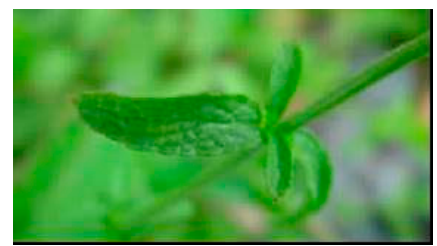

(c)

Figure 5. S. recta L. subsp. subcrenata (a) plant in flowering stage; (b) detail of the flower; (c) detail of leaf.

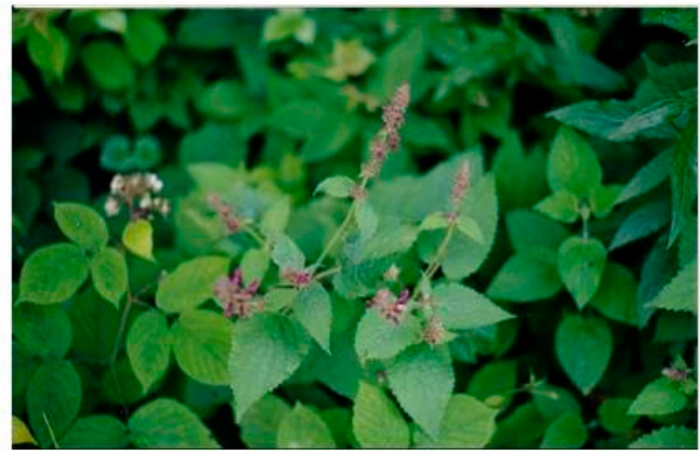

(a)

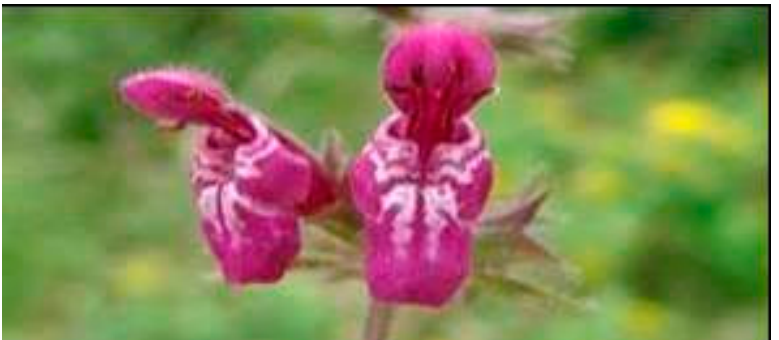

(b)

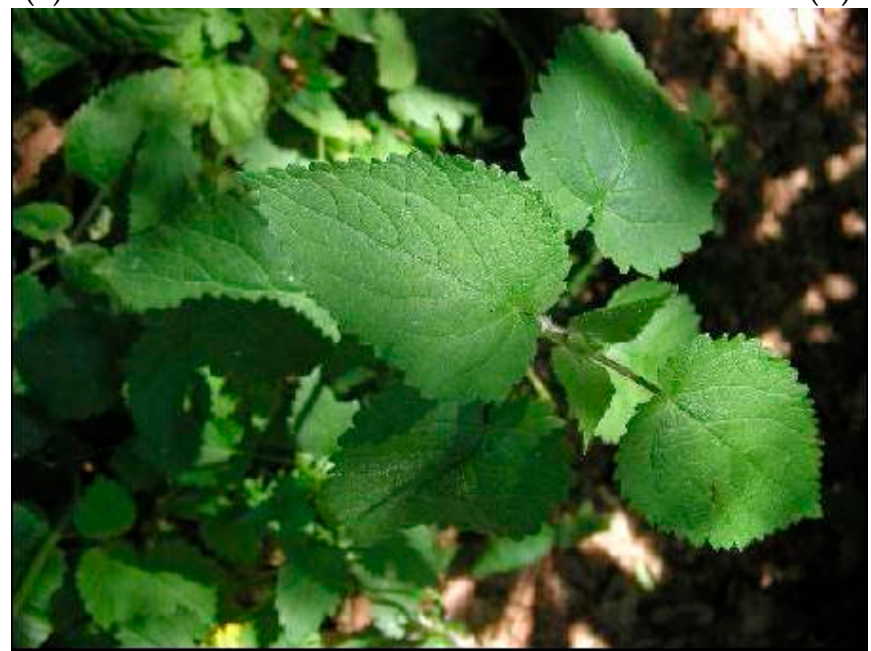

(c)

Figure 6. S. sylvatica L. (a) plant in flowering stage; (b) detail of the flower; (c) detail of leaf.

S. obliqua Waldst. et Kit. is an erect lanate-hirsute perennial with oblong-lanceolate leaves that is native to the Balkan Peninsula [12] [Figure 7].

S.germanica L. (downy woundwort, german hedgenettle) is a densely tomentose and ascendent or erect biennial or perennial with well-marked basal rosettes, growing up to $120 \mathrm{~cm}$ and found in light forests, shrubby sunny slopes, rocks, and cut-over areas [11,12] [Figure 8].

S. salviifolia Ten. (Mediterranean woundwort) is a densely tomentose or lanate-tomentose perennial growing up to about $80 \mathrm{~cm}$ that is widely distributed on rocky places in the littoral areas $[2,3,10,11]$ [Figure 9]. 


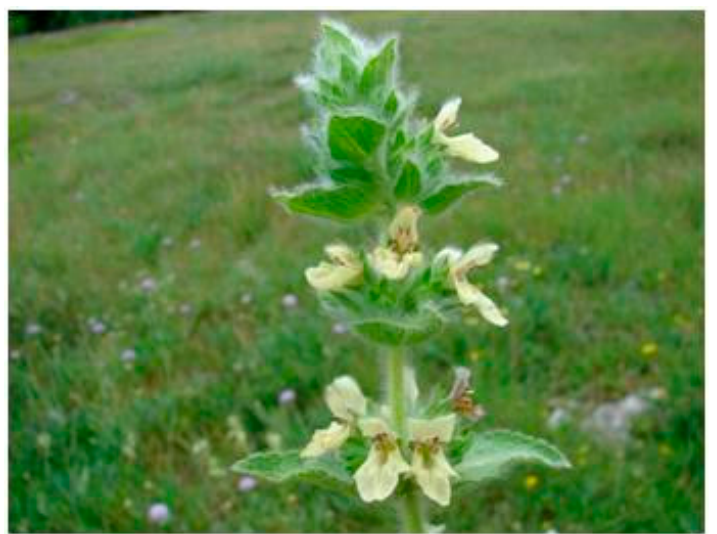

Figure 7. Stachys obliqua Waldst. et Kit. (by courtesy of Saxifraga Foundation).

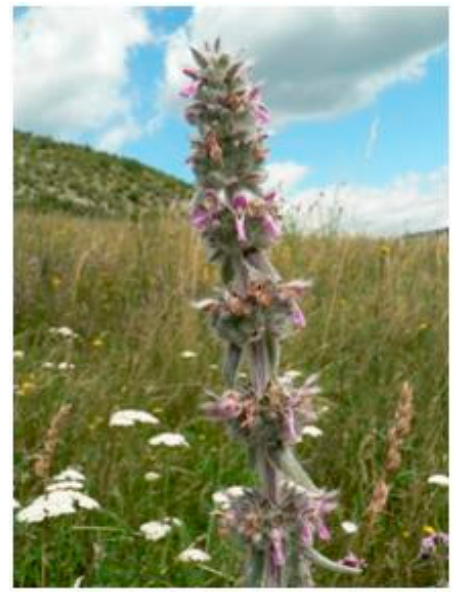

Figure 8. Stachys germanica L. (by courtesy of Saxifraga Foundation).

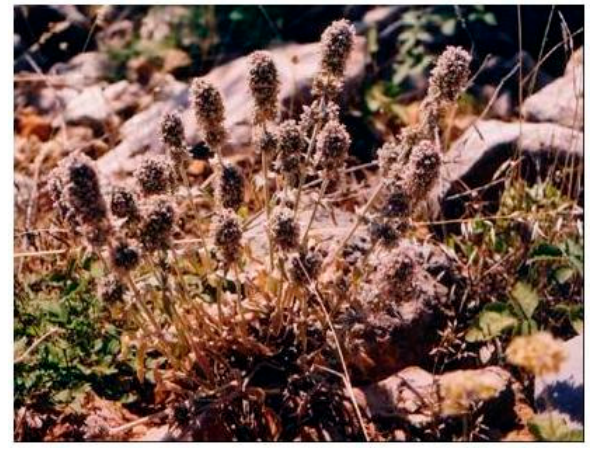

(a)

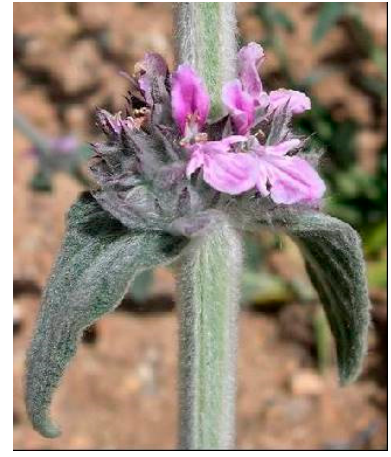

(b)

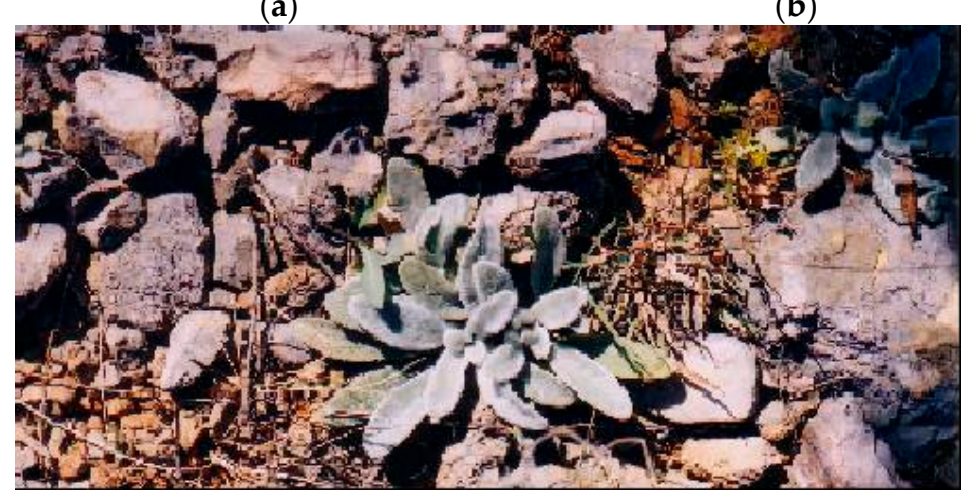

(c)

Figure 9. S. salviifolia Ten. (a) plant in flowering stage; (b) detail of the flower; (c) detail of leaf. 
Stachys menthifolia Vis. is an endemic species that was first described by Roberto Visiani (1829) at the locality of Kotor (Montenegro), who also identified this species in habitat near Dubrovnik (Croatia) [13]. According to the Flora Europaea, the species is endemic of the Balkan Peninsula, and spread in Albania, Greece, and Yugoslavia [3]. In 2002, Šilić and Šolić identified new localities in the eastern part of the Biokovo Massif [9]. S. menthifolia Vis. is a calciphilic plant, with the distinctive feature of a short, glandulary, and pilose stem, and is mostly present in the fissures of limestone or in the open limy rocky grounds, as in the Croatian localities. In the majority of the Montenegrin localities, the plants grow individually or in small groups, often in the strata of thermophilic woods and the underbrush of pubescent oak (Quercetalia pubescentis), in stone fissures, or in open surfaces, while the habitats of the new Croatian localities are mainly open limy rocky grounds with denser populations composed of larger individuals $[9,14,15]$.

\section{Phytochemical Characteristics}

\subsection{Essential Oils}

Similar to many other representatives of the family Lamiaceae, Stachys species produce essential oil. Essential oils are complex mixtures and in spite of the large size of the genus Stachys, the composition of the volatile compounds is known in only a small number of species.

Several studies refer to the composition of the essential oil within the members of the present review: S. alpina [1,10], S. officinalis [1,16-18], S. sylvatica [1,16,17,19-22], S. palustris [1,23], S. germanica [16,17,24], S. menthifolia $[14,15,25]$, S.obliqua [26-28], S. recta $[1,17,25,29-31]$, and S. salviifolia $[1,10]$.

Isocaryophyllene and b-caryophyllene, which are dominating constituents of the previously investigated essential oil from one population of S. officinalis in Montenegro [16], were totally absent in that from a population in Serbia, with germacrene D being the main compound [17]. Another study conducted in Serbia also confirmed sesquiterpene hydrocarbons as being the main fraction and identified germacrene $\mathrm{D}, \beta$-caryophyllene, and $\alpha$-humulene as the main constituents [18].

In a study conducted on samples from Croatia, germacrene D and (E)-caryophyllene were the main compounds of $S$. officinalis, with isocaryophyllene being totally absent [1].

Concerning the prior investigations of S. sylvatica, it is noteworthy that germacrene D is present in a large amount in the sample from Italy [19], and was also present in high proportions in the essential oil from Serbia [17], while the monoterpene fraction is present in all of the samples in a very low percentage only. S. sylvatica essential oil from Croatia was also rich in germacrene D, but in contrast to the oil from Italy and Serbia, monoterpene hydrocarbons were found in a large amount with $\alpha$-pinene and $\beta$-pinene being the most abundant constituents of this fraction. The investigation of the chemical composition of essential oils from S. sylvatica collected from three different wild populations in Kosovo [20] showed that the leaves and flowers of $S$. sylvatica were characterised by three main constituents: $\alpha$-pinene, $\beta$-pinene, and germacrene $D$, which is aligned with the findings on the main constituents that were identified in a study conducted in Croatia. Essential oil obtained from S. sylvatica sample collected in Turkey contained high proportions of germacrene $D, \alpha$-pinene and $\beta$-caryophyllene, but the $\beta$-pinene constituent was not identified [21]. Another study conducted on a S. sylvatica sample collected in Turkey also implicated monoterpene hydrocarbons as the major constituents of essential oil, but with difference in a composition, with $\gamma$-muurolene, $\alpha$-cedrene $(11.2 \%)$, and limonene being the most abundant components [22].

Sesquiterpene hydrocarbons were the main group of essential oil constituents of $S$. salviifolia and S. palustris sample from Croatia, with germacrene D being the main constituent of S. salviifolia, in contrast to $S$. palustris, which contained a significant aldehyde fraction and a high amount of alcohols [1]. The essential oil from the aerial parts of S. palustris from both samples from Italy was characterised mainly by carbonylic compounds, fatty acids, and their esters, along with sesquiterpenoidic compounds and phenols [23,24]. 
The composition of the essential oil from one population of S. recta from Serbia [17] was similar to the oil from a population in Turkey [31] by the preponderance of 1-octen-3-ol. In contrast to the oil from one population in Greece [25] and to the oil from Turkey, in the oil from Serbia, linalool was present in very low percentage only. An analysis of S. recta oil from another population in Serbia revealed a different composition compared to other oils; germacrene $\mathrm{D}$ and E-caryophyllene were the main constituents of the essential oil, while 1-octen-3-ol was present in very low proportions, and linalool was totally absent [17]. The reason for these variations in the chemical composition of the essential oil was probably because there are different subspecies of $S$. recta, which can differ in their essential oil composition.

Two subspecies of $S$. recta (S. recta subsp. recta and S. recta subsp. subcrenata) that were analysed in the Croatian study were collected at the contiguous habitats. Although both subspecies had a high amount of sesquiterpene hydrocarbons, their composition differed; germacrene D was the main component of $S$. recta subsp. subcrenata essential oil, but its level is low in the S. recta subsp. recta oil. S. recta subsp. subcrenata was also characterised by a high percentage of oxygenated sesquiterpenes, whereas $S$. recta subsp. recta had a very low amount of these compounds. On the other hand, S. recta subsp. recta was rich in aldehydes, and had a rather high amount of ketones and fatty acids, which were present in the essential oil of $S$. recta subsp. subcrenata in a very low percentage only [1].

Stachynone and stachynene are constituents of the essential oil of S. officinalis and S. recta, as reported by Maly (1985), and were absent in all of the essential oils that were studied. One reason may be that these compounds decompose in the gas chromatographic injector [29].

Sesquiterpene hydrocarbons were the main group of constituents found in S. menthifolia, as demonstrated for several other Stachys species [25]. Abietatriene and 13-epi-manoyl oxide were present in high amounts in S. menthifolia from Greece [25], while samples collected in two different habitats in Croatia (Biokovo and Dubrovnik) differed in their essential oil composition. The major constituent found in the essential oil from the sample collected in Dubrovnik was, as in the sample from Greece, diterpenoid abietatriene (11.7\%), with significant amounts of sesquiterpene hydrocarbons $\alpha$-bisabolene (8.4\%) and $\beta$-caryophyllene (7.4\%). Oxygenated sesquiterpenes were the most abundant volatiles in the sample from Biokovo, followed by diterpene hydrocarbons. The content of sesquiterpene hydrocarbons was much higher in the sample from Dubrovnik, which also showed no presence of 4'-methoxyacetophenone. The authors attributed the differences in chemical oil composition to the different harvesting dates of the samples [14,15].

The S. alpina sample from Croatia showed the presence of high amounts of oxygenated sesquiterpenes, with a significant aldehyde fraction portion [1]. S. germanica essential oil samples from Serbia and Italy also showed oxygenated sesquiterpenes as the main constituents, with a sample from Serbia having a large amount of monoterpene hydrocarbons as well $(11,3 \%)[17,24]$.

A similar composition was found for S. obliqua samples collected in Turkey, which had a significant portion of monoterpene hydrocarbons and a very high percentage of oxygenated sesquiterpenes with germacrene D as the main constituent [26-28].

A detailed overview of the main components (sesquiterpenes and monoterpenes) in the essential oil of Stachys taxa reviewed is presented in Tables 1 and 2.

Table 1. Main component groups found in Stachys taxa essential oil from aerial parts (monoterpene hydrocarbons: $\mathrm{MH}$; oxygenated monoterpenes: OM; sesquiterpene hydrocarbons: $\mathrm{SH}$; oxygenated sesquiterpenes: OS).

\begin{tabular}{cccccccc}
\hline Taxa & Origin & MH & OM & SH & OS & \multicolumn{2}{c}{ References } \\
\hline S. alpina & Croatia & $/$ & 2.5 & 10.7 & 28.0 & {$[1]$} \\
\hline \multirow{3}{*}{$\begin{array}{c}\text { S. germanica } \\
\end{array}$} & Serbia & 12.3 & 0.8 & 37.8 & 4.8 & {$[17]$} \\
& $\begin{array}{c}\text { Italy, locality Parco Nazionale del Pollino } \\
\text { Italy, locality Parco Nazionale delle } \\
\text { Madonie }\end{array}$ & 0.5 & 0.6 & 20.6 & 4.5 & {$[24]$} & {$[24]$} \\
\hline
\end{tabular}


Table 1. Cont.

\begin{tabular}{|c|c|c|c|c|c|c|}
\hline Taxa & Origin & MH & OM & SH & OS & References \\
\hline \multirow{6}{*}{ S. menthifolia } & Croatia, locality Ploče & 0.3 & 1.7 & 6.4 & 48.4 & [14] \\
\hline & Croatia, locality Dubrovnik & 1.5 & 4.4 & 35.1 & 24.0 & [14] \\
\hline & Croatia, locality Biokovo & $0.1-4.6$ & $1.7-2.9$ & $1.4-6.4$ & $48.4-58.9$ & [14] \\
\hline & $\begin{array}{c}\text { Croatia, locality Vrgorac, alt. } 180 \text { meter } \\
\text { supra mare }\end{array}$ & 0.1 & 2.9 & 1.4 & 58.9 & [14] \\
\hline & $\begin{array}{l}\text { Croatia, locality Vrgorac, alt. 30-130 } \\
\text { meter supra mare }\end{array}$ & 4.6 & 2.4 & 4.2 & 48.4 & {$[14]$} \\
\hline & Greece & 4.3 & 0.5 & 15.3 & 14.2 & [25] \\
\hline S.obliqua & Turkey & 10.3 & / & 72.2 & 4.1 & [26] \\
\hline \multirow{3}{*}{ S. officinalis } & Croatia & 2.4 & 0.3 & 70.4 & 18.7 & [1] \\
\hline & Serbia & 0.3 & 0.4 & 71.1 & 7.7 & [17] \\
\hline & Serbia & 0.8 & 3.7 & 69.1 & 14.8 & [18] \\
\hline \multirow{3}{*}{ S. palustris } & Croatia & / & / & 22.7 & 16.2 & [1] \\
\hline & Italy & & & & & [23] \\
\hline & Italy & 0.5 & 3.1 & 5.4 & 10.6 & [24] \\
\hline \multirow{6}{*}{ S. recta } & Croatia (subs. recta) & 4.1 & 2.9 & 22.2 & 2.1 & [1] \\
\hline & Croatia (subsp. subcrenata) & / & 6.4 & 46.5 & 24.4 & [1] \\
\hline & Serbia & 15.8 & / & 68.7 & 4.1 & [17] \\
\hline & Greece & 1.6 & 41.9 & 6.6 & / & [25] \\
\hline & Serbia & 2.2 & / & 9.3 & 4.6 & {$[30]$} \\
\hline & Turkey & 17.7 & 29.7 & 13.9 & / & [31] \\
\hline \multirow{4}{*}{ S. sylvatica } & Croatia & 38.5 & 0.8 & 41.7 & 7.7 & [1] \\
\hline & Serbia & 3.05 & / & 70.83 & 11.45 & [17] \\
\hline & Italy & 1.7 & / & 72.6 & 6.6 & [19] \\
\hline & Turkey & 48.9 & 1.2 & 32.1 & 2.6 & [22] \\
\hline S. salviifolia & Croatia & 5.3 & 0.8 & 58.4 & 14.9 & [1] \\
\hline
\end{tabular}

Table 2. Main sesquiterpenes and monoterpenes recorded in Stachys taxa (percentige above 5\% presented).

\begin{tabular}{|c|c|c|c|c|}
\hline Compound & Taxa & Origin & $\%$ & References \\
\hline \multirow{8}{*}{ (E)-Caryophyllene } & \multirow{2}{*}{ S. officinalis } & Croatia & 14.6 & [1] \\
\hline & & Serbia & 14.1 & [18] \\
\hline & \multirow{2}{*}{ S. sylvatica } & Croatia & 9.9 & [1] \\
\hline & & Turkey & 20.8 & [21] \\
\hline & S. sylvatica (leaves) & Italy & 31.7 & [19] \\
\hline & S. recta subsp. recta & Croatia & 5.4 & [1] \\
\hline & S. menthifolia & Croatia, locality Dubrovnik & 7.4 & {$[14]$} \\
\hline & S. officinalis & Montenegro & 22.9 & [16] \\
\hline \multirow{5}{*}{ Caryophyllene oxide } & \multirow{3}{*}{ S. palustris } & Croatia & 16.2 & [1] \\
\hline & & Italy & 7.8 & [23] \\
\hline & & Italy & 7.8 & {$[24]$} \\
\hline & S. menthifolia & Croatia, locality Ploče & 5.2 & [14] \\
\hline & S. officinalis & Montenegro & 6.5 & [16] \\
\hline \multirow{11}{*}{ Germacrene D } & S. obliqua & Croatia & 20.1 & {$[1]$} \\
\hline & \multirow{2}{*}{ S. officinalis } & Turkey & 45.3 & [26] \\
\hline & & Serbia & 19.9 & [18] \\
\hline & S. recta subsp. subcrenata & Croatia & 19.7 & [1] \\
\hline & S. salviifolia & Croatia & 22.3 & [1] \\
\hline & \multirow{2}{*}{ S. sylvatica } & Croatia & 13.6 & [1] \\
\hline & & Turkey & 23.9 & [21] \\
\hline & S. sylvatica (inflorescence) & Italy & 55.2 & [19] \\
\hline & S. sylvatica (leaves) & Italy & 31.7 & [19] \\
\hline & \multirow{2}{*}{ S. obliqua } & Turkey & 8.2 & [27] \\
\hline & & Turkey & 6.2 & [28] \\
\hline
\end{tabular}


Table 2. Cont.

\begin{tabular}{|c|c|c|c|c|}
\hline Compound & Taxa & Origin & $\%$ & References \\
\hline$\alpha$-Humulene & S. officinalis & Serbia & 7.5 & [18] \\
\hline \multirow{2}{*}{$\alpha$-Pinene } & \multirow{2}{*}{ S. sylvatica } & Croatia & 21.4 & [1] \\
\hline & & Turkey & 19.6 & [21] \\
\hline$\beta$-Pinene & S. sylvatica & Croatia & 12.3 & [1] \\
\hline Linalool & S.recta & Turkey & 13.0 & {$[31]$} \\
\hline$(-)-\beta$-Linalool & S.recta & Greece & 33.9 & [25] \\
\hline (E)-Nerolidol & S. alpina & Croatia & 12.3 & [1] \\
\hline$\gamma$-Cadinene & S. recta subsp. recta & Croatia & 6.9 & [1] \\
\hline$\delta$-Cadinene & S. sylvatica (leaves) & Italy & 31.7 & [19] \\
\hline$\alpha$-Cadinol & S. recta subsp. subcrenata & Croatia & 9.5 & [1] \\
\hline$\beta$-Elemene & S. salviifolia & Croatia & 9.4 & [1] \\
\hline$\alpha$-Bisabolene & S. menthifolia & Croatia, locality Dubrovnik & 7.4 & [14] \\
\hline Valeranone & S. menthifolia & $\begin{array}{l}\text { Croatia, locality Vrgorac, alt. } \\
\text { 30-130 meter supra mare }\end{array}$ & 5.7 & [14] \\
\hline \multirow{3}{*}{ 8- $\alpha$-Acetoxyelemol } & \multirow{3}{*}{ S. menthifolia } & $\begin{array}{l}\text { Croatia, locality Vrgorac, alt. } 180 \\
\text { meter supra mare }\end{array}$ & 21.3 & \multirow{3}{*}{ [14] } \\
\hline & & $\begin{array}{l}\text { Croatia, locality Vrgorac, alt. } \\
\text { 30-130 meter supra mare }\end{array}$ & 6.9 & \\
\hline & & Croatia, locality Ploče & 12.8 & \\
\hline \multirow{2}{*}{ Limonene } & S. obliqua & Turkey & 6.2 & [28] \\
\hline & S. sylvatica & Turkey & 37.0 & [22] \\
\hline \multirow{2}{*}{ Thymol } & S. obliqua & Turkey & 6.2 & [28] \\
\hline & S. palustris & Italy & 5.8 & [23] \\
\hline$\alpha$-Cedrene & S. sylvatica & Turkey & 37.0 & [22] \\
\hline$\gamma$-Muurolene & S. sylvatica & Turkey & 10.2 & [22] \\
\hline
\end{tabular}

\subsection{Other Biologically Active Substances}

Similar to most of the plants belonging to the Lamiaceae family, the Stachys taxa have been submitted to several investigations in order to determine the content of the biologically active compounds. These investigations have reported the presence of flavonoids, phenolic acids, iridoids, and terpenoids.

Bilušić Vundać et al. investigated seven Croatian Stachys taxa (S. alpina, S. officinalis, S. palustris, S. recta subsp. recta, S. recta subsp. subcrenata, S. salviifolia, and S. sylvatica) in order to determine the content of the polyphenols, tannins, phenolic acids, and flavonoids, as well as the composition of flavonoids and phenolic acids. All of the taxa that were tested had a high content of total polyphenols, a medium content of total phenolic acids, and a rather low content of tannins and flavonoids. The most present phenolic compound in the investigated samples was found to be the chlorogenic acid (it was not present only in $S$. recta subsp. recta), and in samples of $S$. recta subsp. recta and $S$. sylvatica, the presence of isoquercitrin, luteolin-7-O-glucoside, and quercitrin were determined. Rutin was determined in samples of $S$. recta subsp. recta, S. recta subsp. subcrenata, S. sylvatica, and S. salviifolia. Although S. recta subsp. recta didn't contain chlorogenic acid, it was found to be the richest in flavonoids whose presence was determined [32,33].

Karioti et al. (2010) determined 14 flavonoid glycosides in S. recta, with the majority of the constituents being the derivatives of isoscutellarein, and there being only four apigenin- $p$-coumaroyl derivatives [34]. 
Tundis et al. (2014) reviewed all of the available data on the biologically active substances in Stachys taxa, and found the following diterpenes to be present in the taxa that are included in this review: annuanone, stachylone, and stachone (S. palustris, S. sylvatica); abietal, abietatriene, stachysic acid, scareol, trans-Phytol, 6 $\beta$-hydroxy-ent-kaur-16-ene, 6b,18-dihydroxy-ent-kaur-16-ene, kaur-16-ene,13-epi-manoyl oxide, and betolide (S. sylvatica); betonicoside A-D and trans-Phytol (S. officinalis); abietatriene, abieta-8, 11, 13-trien-7-one, 13-epi-manoyl oxide, cis-Phytol, and Labd-13-en-8,15-ol and kaur-16-ene (S.menthifolia); abietatriene and epi-Laurenene (S. germanica); and cis-Phytol, 11 $\alpha, 18$-dihydroxy-ent-kaur-16-ene, kaur-16-ene, diacetyl derivatives, and monoacetyl derivatives of stachysolone (S. recta). Furthermore, in their overview of data on iridoids isolated in Stachys taxa, the following compounds were determined for the taxa presented: S. recta and S. alpina contained harpagide, ajugoside, aucubin, acetylharpagide, and harpagoside; S. germanica contained harpagide, aucubin, acetylharpagide, and harpagoside, S. palustris contained harpagide and aucubin; while S. alpina contained harpagide, ajugoside, aucubin, and harpagoside [35]. Furthermore, recent research studies of the active substances in S. palustis identified not only iridoids harpagide and 8-O-acetyl-harpagide, but also monomelittoside, which was the first identification of this compound in S. palustris species [36].

Bilušić Vundać (2006) identified several amino acids in Stachys species: aspartic acid (S. alpina, S. sylvatica, S. officinals, and S. salviifolia), asparagine (S. sylvatica, S. alpina, and S. recta subsp. subcrenata), $\gamma$-aminobutyric acid were determined in all of the investigated taxa (S. alpina, S. officinalis, S. palustris, S. recta subsp. recta, S. recta subsp. subcrenata, S. salviifolia, and S. sylvatica), as well as alanine, leucine, and serine [37].

\section{Discussion and Conclusions}

The presented studies revealed some differences between Stachys taxa, indicating the existence of a chemical polymorphism. The taxonomic relationships within the taxa are complex, and have been the objective of several investigations. Although different types of biologically active substances were determined within the investigated Stachys species, the main differentiation is based on essential oil and fatty acid composition. Tundis et al. (2014) focused on taxonomy within Stachys and Betonica subgenera, as well as infrageneric differentiation within Stachys species focusing on these chemotaxonomical markers. Based on the collected data on essential oil, three groups of Stachys species were observed: species mainly characterised by monoterpene hydrocarbons (to which S. sylvatica was assigned), species mainly characterised by oxygenated monterpenes (to which $S$. recta was assigned), and species that contain similar amounts of sesquiterpene hydrocarbons and oxygenated sesquiterpenes [35].

The essential oil approach, including its fatty acid composition, was taken by Bilušić Vundać (2006), who through principal components (PCA) and hierarchical cluster analyses (CA) differentiated seven Stachys taxa to two distinct groups, first comprising S. alpina, S. recta subsp. Recta, and S. palustris, and second comprising S. officinalis, S. sylvatica, S. recta subsp. subcrenata, and S. salviifolia. The species within the first group showed a high content of aldehyde components, and in the case of S. alpina and S. palustris, a high content of alcohol, while in the species within the second group, germacrene D was identified as the main component.

The essential oil and fatty acid approach was also used in chemotaxonomic differentiation by Kiliç at al. (2017), who defined germacrene $D / \beta$-caryophyllene the essential oil chemotype and 6-octadecanoic acid fatty acid chemotype for S. sylvatica [21].

The chemical investigations of Stachys species have determined the presence of monterpenes, sesquiterpenes, diterpenes, iridoids, phenylethanoids, flavonoids, and fatty acids as the main biological constituents. The content of these components and their occurrence in investigated species is variable, due to many external factors that impact the secondary metabolite composition of the plant species $[1,35]$.

The differentiation of the presented Stachys species based on the available data on their chemical composition requests further chemotaxonomical and molecular research in order to present a key for infrageneric classification. Througout history, basic plant species and subspecies identification 
has relied mostly on morphological traits. For morphological characterisation, taxonomists have formulated a descriptor list, such as leaf shape and colour, flower colour, etc. With the development of scientific methods, chemotaxonomy research increased in order to enable separation within the taxa based on the presence and quantity of a specific chemical compound [38]. In recent studies, the authors have tried to resolve the classification of Stachys taxa based on the prevalent essential oil compositions from the aerial parts $[10,21,26]$. Nevertheless, the results vary, since different geographic localities, seasons, harvest periods, properties of soils, and climatic conditions strongly affect the secondary metabolite composition of plant species, especially their essential oil composition $[1,21,35]$. Therefore, traditional evaluation methods and chemotaxonomy should be combined with molecular markers that are not influenced by the environmental factors, for a better distinction among Stachys taxa.

Taking all of the above into consideration, a potential suggestion for differentiation can be suggested within the presented investigations only for two $S$. recta subspecies, which were collected at identical conditions and habitat (time of collection, harvest period, soil, and climate), which could support the opinion of Visiani (1829), who described S. recta subsp. subcrenata as separate species and named it S. subcrenata [10].

Although many constituents of this genus have been already identified, further investigations of Stachys spp. are required in order to clearly identify the chemotaxonomical markers for specific taxa and clarify their taxonomic relationships.

Funding: This research received no external funding.

Acknowledgments: The author would like to thank Saxifraga Foundation (http://www.saxifraga.nl) for providing photos of S. obliqua (photo by Jasenka Topić) and S. germanica (photo by Jan Willem Jongepier).

Conflicts of Interest: The author declares no conflict of interest.

\section{References}

1. Bilušić Vundać, V.; Pfeifhofer, H.W.; Brantner, A.H.; Maleš, Ž.; Plazibat, M. Essential oil of seven Stachys taxa from Croatia. Biochem. Syst. Ecol. 2006, 34, 875-881. [CrossRef]

2. Domac, R. Flora of Croatia and Neighbouring Areas; Školska Knjiga: Zagreb, Hrvatska, 1973; pp. 332-335.

3. Ball, P.W. Stachys L. In Flora Europaea; Tutin, T.G., Heywood, V.H., Burges, N.A., Moore, D.M., Valentine, D.H., Walters, S.M., Webb, D.A., Eds.; Cambridge University Press: Cambridge, UK, 1972; Volume 3, pp. 151-157.

4. Bhattacharjee, R. Taxonomic studies in Stachys: II. A new infrageneric classification of Stachys L. Notes Roy. Bot. Gard. Edinbourgh 1980, 38, 65-96.

5. Mulligan, G.A.; Munro, D.B. Taxonomy of species of North American Stachys (Labiatae) found in north of Mexico. Rev. Ecol. Syst. 1989, 116, 35-51.

6. Turner, B.L. Synopsis of Mexican and Central American species of Stachys (Lamiaceae). Phytologia 1994, 77, 338-377. [CrossRef]

7. Falciani, L. Systematic revision of Stachys sect. Eriostomum (Hofmans \& Link) Dumort. in Italy. Lagascalia 1997, 19, 187-237.

8. Lovašen-Ebberhardt, Ž. Stachys L. In Index Florae Croaticae 3; Nikolić, T., Ed.; Hrvatski Prirodoslovni Muzej: Zagreb, Croatia, 2000; pp. 24-25.

9. Šilić, Č.; Šolić, M.E. The taxonomy, chorology and ecology of Stachys menthifolia Vis. (Lamiaceae) in the north-west part of its distribution area. Acta Bot. Croat. 2002, 61, 51-56.

10. Bilušić Vundać, V. Pharmacobotanical and Chemotaxonomical Characterisation of Some Stachys Taxa (Lamiaceae). Ph.D. Thesis, University of Pharmacy and Biochemistry, Zagreb, Croatia, 2006.

11. Forenbacher, S. Velebit i Njegov Biljni Svijet; Školska knjiga: Zagreb, Croatia, 1990; pp. 581-583.

12. Region Bojňanský, V.; Fargašová, A. Atlas of Seeds and Fruits of Central and East-European Flora The Carpathian Mountains; Springer: Dordrecht, The Netherlands, 2007; p. 1046. ISBN1 978-1-4020-5361-0. ISBN2 978-1-4020-5362-7.

13. Visiani, R. Plantae Rariores in Dalmatia Recens Detectae. Flora (Regensb.) 1829, 12, 1-24.

14. Ćavar, S.; Maksimović, M.; Šolić, M.E. Comparison of Essential Oil Composition of Stachys menthifolia Vis. from Two Natural Habitats in Croatia. Biol. Nyssana 2010, 1, 99-103. 
15. Ćavar, S.; Maksimović, M.; Vidic, D.; Šolić, M.E. Chemical composition of the essential oil of Stachys menthifolia Vis. Pharm. Biol. 2010, 48, 170-176. [CrossRef]

16. Chalchat, J.C.; Petrović, S.D.; Maksimović, Z.A.; Gorunović, M.S. Essential oil of Stachys officinalis (L.) Trevis, Lamiaceae, from Montenegro. J. Essent. Oil Res. 2001, 13, 286-287. [CrossRef]

17. Grujić-Jovanović, S.; Skaltsa, H.D.; Marin, P.; Soković, M. Composition and antibacterial activity of the essential oil of six Stachys species from Serbia. Flavour Fragr. J. 2004, 19, 134-144. [CrossRef]

18. Lazarević, J.S.; Đorđević, A.S.; Kitić, D.V.; Zlatković, B.K.; Stojanović, G.S. Chemical composition and antimicrobial activity of the essential oil of Stachys officinalis (L.) Trevis. (Lamiaceae). Chem. Biodivers. 2013, 10, 1335-1349. [CrossRef]

19. Tirillini, B.; Pellegrino, R.; Bini, L.M. Essential oil composition of Stachys sylvatica from Italy. Flavour Fragr. J. 2004, 19, 330-332. [CrossRef]

20. Hajdari, A.; Novak, J.; Mustafa, B.; Franz, C. Essential oil composition and antioxidant activity of Stachys sylvatica L. (Lamiaceae) from different wild populations in Kosovo. Nat. Prod. Res. 2012, 26, 1676-1681. [CrossRef] [PubMed]

21. Kiliç, Ö.; Özdemir, F.; Şinasi, Y. Essential oils and fatty acids of Stachys L. taxa, a chemotaxonomic approach. Prog. Nutr. 2017, 19, 49-59. [CrossRef]

22. Renda, G.; Bektaş, N.Y.; Korkmaz, B.; Celik, G.; Sevgi, S.; Yayl, N. Volatile Constituents of three Stachys L. species from Turkey. Marmara Pharm. J. 2017, 21, 278-285. [CrossRef]

23. Senatore, F.; Formisano, C.; Rigano, D.; Piozzi, F.; Rosselli, S. Chemical composition of the essential oil from aerial parts of Stachys palustris L. (Lamiaceae) growing wild in Southern Italy. Croat. Chem. Acta 2007, 80, 135-139.

24. Conforti, F.; Menichini, F.; Formisano, C.; Rigano, D.; Senatore, F.; Arnold, N.A.; Piozzi, F. Comparative chemical composition, free radical-scavenging and cytotoxic properties of essential oils of six Stachys species from different regions of the Mediterranean Area. Food Chem. 2006, 116, 898-905. [CrossRef]

25. Skaltsa, H.D.; Demetzos, C.; Lazari, D.; Sokovic, M. Essential oil analysis and antimicrobial activity of eight Stachys species from Greece. Phytochemistry 2003, 64, 743-752. [CrossRef]

26. Goren, A.C.; Piozzi, F.; Akçicek, E.; Kılıc, T.; Carıkc, S.; Mozioǵlu, E.; Setzer, W.N. Essential oil composition of twenty-two Stachys species (mountain tea) and their biological activities. Phytochem. Lett. 2011, 4, 448-453. [CrossRef]

27. Demirci, B.; Yıldız, G.; Kırımer, N.; Ocak, A.; Hüsnü Can Başer, K. Essential oil composition of Stachys obliqua Waldst. et Kit. Nat. Volatiles Essent. Oils 2018, 5, 17-22.

28. Harmandar, M.; Duru, M.E.; Cakir, A.; Hirata, T.; Izumi, S. Volatile constituents of Stachys obliqua L. (Lamiaceae) from Turkey. Flavour Fragr. 1997, 12, 211-213. [CrossRef]

29. Maly, E. Paper chromatography of the essential oils occuring in the genus Stachys. J. Chromatogr. 1985, 333, 288-289. [CrossRef]

30. Chalchat, J.C.; Petrović, S.D.; Maksimović, Z.A.; Gorunović, M.S. Essential oil of the herb of Stachys recta L., Lamiaceae, from Serbia. J. Essent. Oil Res. 2000, 12, 455-458. [CrossRef]

31. Cakir, A.; Duru, M.E.; Harmandar, M.; Izumi, S.; Hirata, T. The volatile constituents of Stachys recta L. and Stachys balansae L. from Turkey. Flavour Fragr. J. 1997, 12, 215-218. [CrossRef]

32. Bilušić Vundać, V.; Brantner, AH.; Miško, P. Content of polyphenolic constituents and antioxidant activity of some Stachys taxa. Food Chem. 2007, 104, 1277-1281. [CrossRef]

33. Bilušić Vundać, V.; Maleš, Ž.; Plazibat, M.; Golja, P.; Cetina-Čižmek, B. HPTLC determination of flavonoids and phenolic acids in some Croatian Stachys taxa. J. Planar Chromatogr. 2005, 18, 269-273. [CrossRef]

34. Karioti, A.; Bolognesi, L.; Vincieri, F.F.; Bilia, A.R. Analysis of the constituents of aqueous preparations of Stachys recta by HPLC-DAD and HPLC-ESI-MS. J. Pharm. Biomed. Anal. 2010, 53, 15-23. [CrossRef]

35. Tundis, R.; Peruzzi, L.; Menichini, F. Phytochemical and biological studies of Stachys species in relation to chemotaxonomy: A review. Phytochemistry 2014, 102, 7-39. [CrossRef] [PubMed]

36. Frezza, C.; Venditti, A.; Maggi, F.; Cianfaglione, K.; Nagy, D.U.; Serafini, M.; Bianco, A. Secondary metabolites from Stachys palustris L. In Proceedings of the 6th International Congress of Aromatic and Medicinal Plants (CIPAM 2016), Coimbra, Portugal, 29 May-1 June 2016; Salgueiro, L., Cavaleiro, C., Cabral, C., Eds.; Universidade de Coimbra: Coimbra, Portugal, 2016; p. 80. ISBN 978-989-95050-1-8. 
37. Bilušić Vundać, V. Qualitative and quantitative determination of amino acids in some Stachys taxa-Part of PhD thesis 'Pharmacobotanical and chemotaxonomical characterisation of some Stachys taxa (Lamiaceae). 2006. Available online: https://www.researchgate.net/publication/327651956_ Qualitative_and_quantitative_determination_of_aminoacids_in_some_Stachys_taxa_part_of_PhD_thesis_ \%27Pharmacobotanical_and_chemotaxonomical_characterisation_of_Some_Stachys_taxa_Lamiaceae\%27 (accessed on 2 December 2018).

38. Chowdhury, T.; Mandal, A.; Roy, SC.; De Sarker, D. Diversity of the genus Ocimum (Lamiaceae) through morpho-molecular (RAPD) and chemical (GC-MS) analysis. J. Genet. Eng. Biotechnol. 2017, 15, 275-286. [CrossRef]

(C) 2019 by the author. Licensee MDPI, Basel, Switzerland. This article is an open access article distributed under the terms and conditions of the Creative Commons Attribution (CC BY) license (http:/ / creativecommons.org/licenses/by/4.0/). 